\title{
Large Congenital Melanocytic Nevus With Halo Phenomenon
}

\author{
Filiz Cebeci ${ }^{1}$, Hasan Aksoy $^{1}$, Zeynep Arslan ${ }^{1}$, Bengü Çobanoğlu Şimşek ${ }^{2}$
}

\begin{abstract}
1 Department of Dermatology, Istanbul Medeniyet University, Goztepe Suleyman Yalcin City Hospital, Istanbul, Turkey
2 Department of Pathology, Istanbul Medeniyet University, Goztepe Suleyman Yalcin City Hospital, Istanbul, Turkey
\end{abstract}

Key words: Congenital melanocytic nevus, Halo phenomenon

Citation: Cebeci F, Aksoy H, Arslan Z, Şimşek BC. Large congenital melanocytic nevus with halo phenomenon. Dermatol Pract Concept. 2022;12(1):e2022016. DOI: https://doi.org/10.5826/dpc.1201a16

Accepted: May 8, 2021; Published: January 2022

Copyright: $@ 2022$ Cebeci et al. This is an open-access article distributed under the terms of the Creative Commons Attribution License BY-NC-4.0, which permits unrestricted noncommercial use, distribution, and reproduction in any medium, provided the original authors and source are credited.

Funding: None.

Competing interests: None.

Authorship: All authors have contributed significantly to this publication.

Corresponding author: Filiz Cebeci Assoc. Prof, Department of Dermatology, Istanbul Medeniyet University, Goztepe Suleyman Yalcin City Hospital, Istanbul, Turkey. Email: E-mail:cebecifiliz@yahoo.com

\section{Introduction}

Congenital melanocytic nevus (CMN) is a pigmented lesion present at birth or appearing in the first few weeks of life, with an incidence of $0.6 \%-1.6 \%$ among newborns. It develops from neural crest-derived melanocytes and usually enlarges throughout childhood. A CMN may remain unchanged or present a dynamic course [1,2]. Halo nevus or leukoderma acquisitum centrifugum can be defined by the presence of circular depigmentation around an acquired or congenital nevus; a halo can also develop around a melanoma. Herein, we report a male adolescent with halo phenomenon around a large $\mathrm{CMN}$, an uncommon finding.

\section{Case Presentation}

A 14-year-old boy was admitted to our department due to complaint of enlargement and color change of a nevus on his right shin. The lesion had been present since birth and has grown over the years; during the past year, whitening of the skin was noted to develop around it. On physical examination, there was a $12 \mathrm{~cm} \times 5.5 \mathrm{~cm}$ ellipsoid pigmented patch containing irregularly mottled hypopigmentation and few depigmented terminal hairs, surrounded by a $0.5-\mathrm{cm}$ wide depigmented halo-like patch (Figure 1A). Dermoscopy showed regular network and globules, suggesting that the pigmented patch was melanocytic in origin (Figure 1B). The lesion was biopsied and histopathology revealed hypermelanosis at the basal cell layer, nests of nevomelanocytes in the dermis and periadnexial lymphocytic infiltration; in the areas corresponding to the depigmented part of the lesion, epidermal melanin and dermal nevus cells were notably absent (Figure 2, A-D). Based on the clinical and histopathological findings, the diagnosis was a large $\mathrm{CMN}$ with a halo phenomenon.

\section{Conclusions}

A halo phenomenon around a nevus has been suggested to be due to immunologic responses against melanocytes mediated 


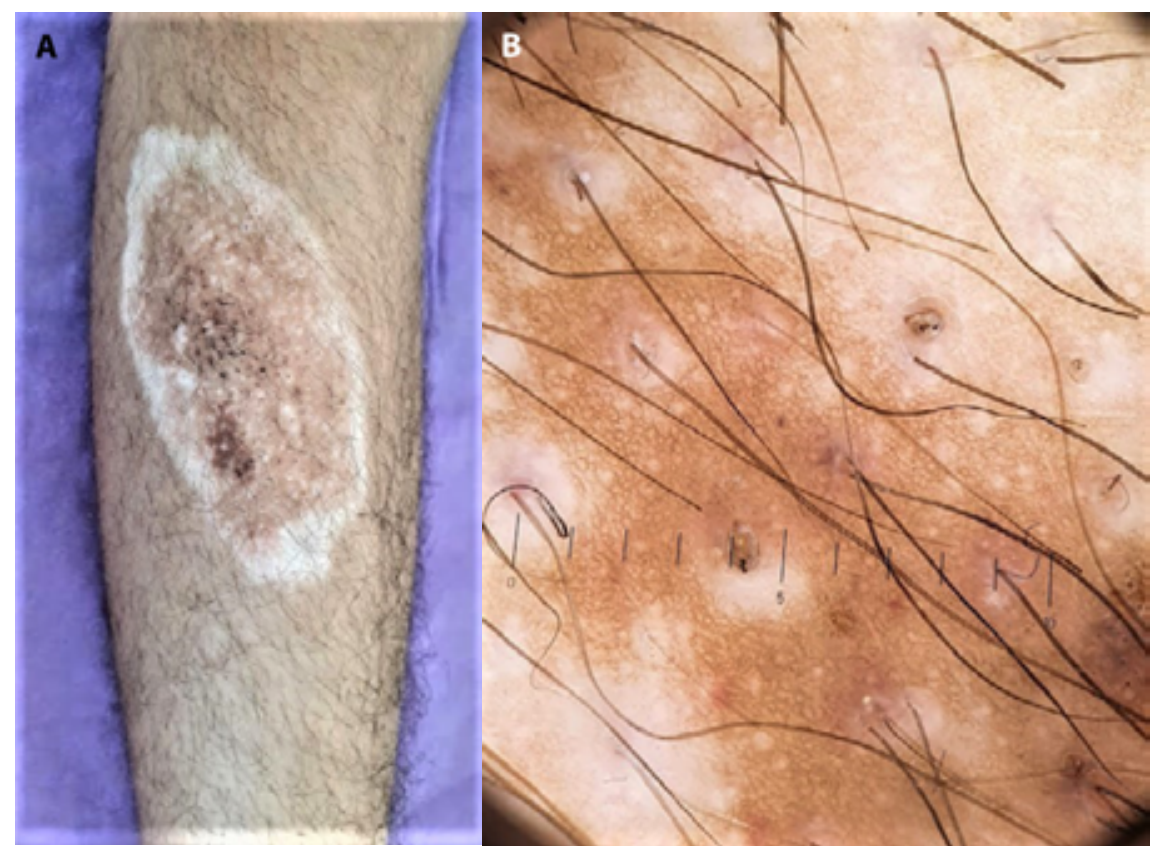

Figure 1. (A) Melanocytic patch with irregularly mottled hypopigmentation, depigmented terminal hairs, and a depigmented halo. (B) Regular network, a few pigmented globules, and depigmented areas on dermoscopy.

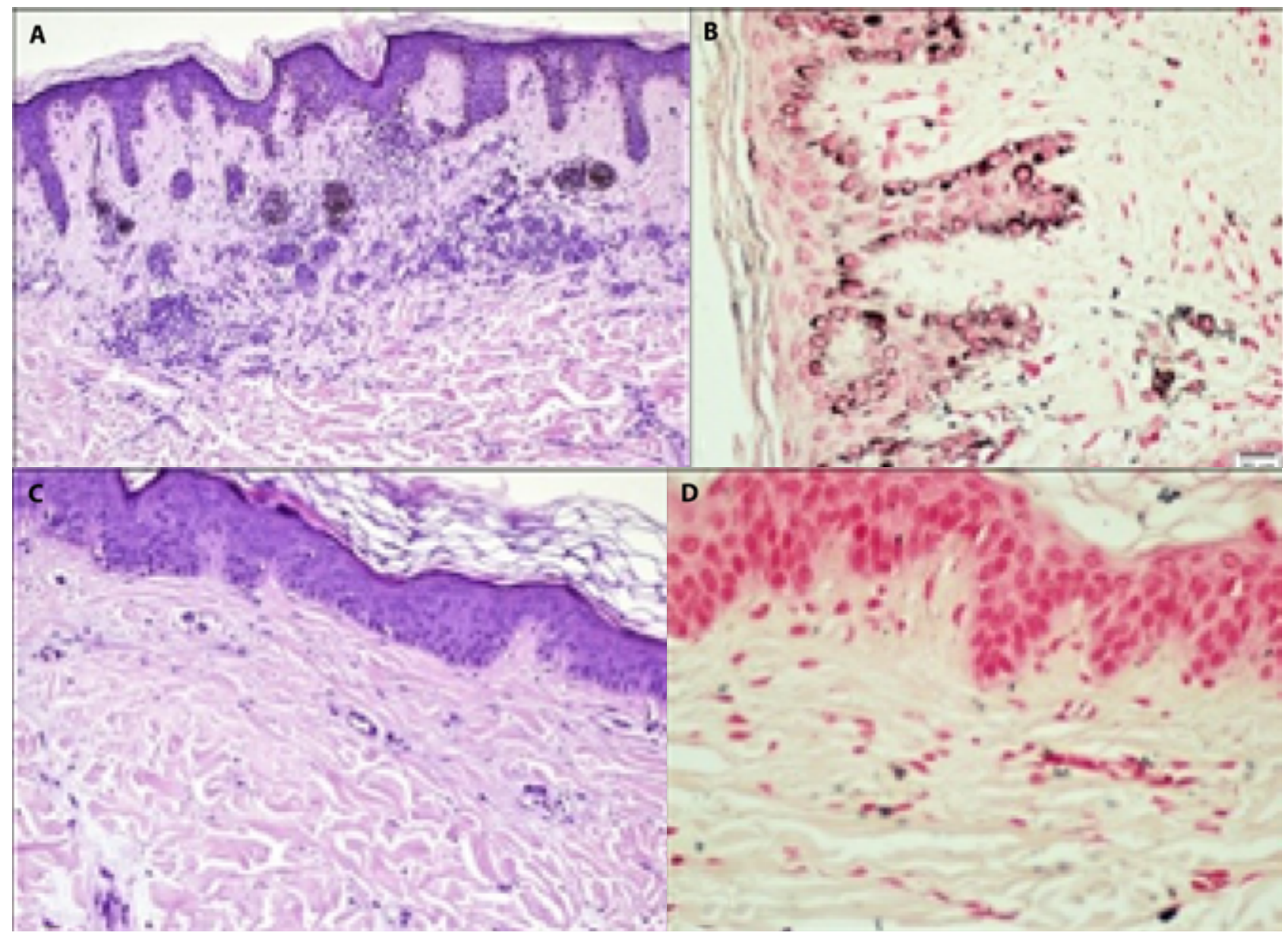

Figure 2. Histopathology of the lesion. (A) Intradermal nevoid nests consistent with congenital melanocytic nevus. (B) Hypermelanosis in the epidermal basal cell layer corresponding to the hyperpigmented area. (C) Loss of epidermal melanin and dermal nevomelanocytes corresponding to the depigmented part of the lesion $(H \& E, \times 200)$. (D) Loss of melanin in the basal cell layer (Masson-Fontana, $\times 400)$. 
by cytotoxic T-cells or immunoglobulin $\mathrm{M}$ autoantibodies [2]. Unlike acquired nevi, the development of halo around a large congenital nevus is less common. Halo around $\mathrm{CMN}$ may also be accompanied by vitiligo. A CMN with a halo may eventuate in partial or complete regression of the pigmented lesion with progressive depigmentation, remain stable, or undergo repigmentation. Spontaneous involution of a $\mathrm{CMN}$ is uncommon [1,2]. Halo phenomenon around a CMN usually causes anxiety and may result in unnecessary surgical procedures. However, it is usually a benign condition and CMN patients with halo phenomenon should be followed up periodically, just as those with CMN without a halo phenomenon. It is suggested that a conservative approach and dermoscopic follow-up are safe for children with a CMN. Development of depigmentation around or within the CMN may be confused with pigmentary regression and conversion to malignant melanoma, and thus it is important to be aware of this phenomenon to avoid premature surgery, especially in children.

Informed consent: Informed consent for publication of clinical details and clinical images was obtained from the patient.

\section{References}

1. Karvonen SL, Vaajalahti P, Marenk M, Janas M, Kuokkanen K. Birthmarks in 4346 Finnish newborns. Acta Derm Venereol. 1992;72(1):55-57. PMID: 1350148.

2. Lee NR, Chung HC, Hong H, Lee JW, Ahn SK. Spontaneous involution of congenital melanocytic nevus with halo phenomenon. Am J Dermatopathol. 2015;37(12):e137-e139. DOI: 10.1097/DAD.000000000000311. PMID: 26588343. PMCID: PMC4894811. 